\title{
Health insurance mediation of the Mexican American non-Hispanic white disparity on early breast cancer diagnosis
}

\author{
Sundus Haji-Jama ${ }^{1}$, Kevin M Gorey ${ }^{1 *}$, Isaac N Luginaah², Madhan K Balagurusamy ${ }^{1}$ and Caroline Hamm ${ }^{3,4}$
}

\begin{abstract}
We examined health insurance mediation of the Mexican American (MA) non-Hispanic white (NHW) disparity on early breast cancer diagnosis. Based on social capital and barrio advantage theories, we hypothesized a 3-way ethnicity by poverty by health insurance interaction, that is, that 2-way poverty by health insurance interaction effects would differ between ethnic groups. We secondarily analyzed registry data for $303 \mathrm{MA}$ and 3,611 NHW women diagnosed with breast cancer between 1996 and 2000 who were originally followed until 2011. Predictors of early, node negative (NN) disease at diagnosis were analyzed. Socioeconomic data were obtained from the 2000 census to categorize neighborhood poverty: high (30\% or more of the census tract households were poor), middle (5\% to 29\% poor) and low (less than 5\% poor). Barrios were neighborhoods where 50\% or more of the residents were MA. Primary health insurers were Medicaid, Medicare, private or none. MA women were 13\% less likely to be diagnosed early with NN disease $(R R=0.87)$, but this MA-NHW disparity was completely mediated by the main and interacting effects of health insurance. Advantages of health insurance were largest in low poverty neighborhoods among NHW women $(R R=1.20)$ while among MA women they were, paradoxically, largest in high poverty, MA barrios ( $R R=1.45)$. Advantages of being privately insured were observed for all. Medicare seemed additionally instrumental for NHW women and Medicaid for MA women. These findings are consistent with the theory that more facilitative social and economic capital is available to MA women in barrios and to NHW women in more affluent neighborhoods. It is there that each respective group of women is probably best able to absorb the indirect and direct, but uncovered, costs of breast cancer screening and diagnosis.
\end{abstract}

Keywords: Mexican American; Barrio; Gateway neighborhood; Poverty; Health insurance; Breast cancer; Early diagnosis

\section{Background}

During what has come to be known as the Great Recession, the census bureau estimated that the prevalence of poverty had increased nearly $25 \%$ in America over only four years (from 37.5 million in 2007 to 46.2 million in 2011). During the same era the prevalence of Americans without health insurance increased by more than $10 \%$ to 50 million (DeNavas-Walt et al. 2012). But if the underinsured were included, the estimate doubled to 100 million or approximately one of every three Americans (Kaiser Family Foundation 2012). When viewed through an ethnic lens, such inequities are even more startling.

\footnotetext{
* Correspondence: gorey@uwindsor.ca

${ }^{1}$ School of Social Work, University of Windsor, 401 Sunset Avenue, Windsor, Ontario N9B 3P4, Canada

Full list of author information is available at the end of the article
}

For example, the prevalence of being uninsured among Hispanic Americans (32.4\%) was estimated to be nearly three times greater than among non-Hispanic white (NHW) Americans in 2009 (12.0\% (Kaplan \& Inguanzo 2011)). And among Hispanics, the prevalence was highest among Mexican Americans (MA), four of every ten of them lacking any form of health insurance, public or private (Miranda et al. 2011).

Even in the decade that preceded the great recession, the social risks that arose out of being uninsured and poor were stronger in some places and among some people. In California, the state with the largest MA population, the concentration of poor people into extremely poor neighborhoods rose substantially. And among Hispanic people, MA women in particular, the concentrations of the poorest poor and the least insured into so-called barrios were 
dramatic (Acosta 2010; Berube \& Frey 2005; Jargowsky 2005). Our research group has been analyzing the effects of these social forces on cancer care in California over the past 15 years (Gorey et al. 2011; Gorey et al. 2009). This study aims to connect this work to the burgeoning social capital-based theoretical explanations for the Hispanic paradox. Diverse health benefits seem to be enjoyed by otherwise quite socioeconomically vulnerable people who live in Hispanic enclaves (Keegan et al. 2010a; Mair et al. 2010; Cagney et al. 2007), especially in barrio neighborhoods that are predominantly populated by first generation immigrants from Mexico (Osypuk et al. 2010). When discussing healthcare disparities that Hispanics might face, it is important to analyze different Hispanic groups separately and avoid the risk of missing important clinical and social differences. Different groups may face different obstacles to accessing healthcare resources (Miranda et al. 2011).

Focusing on the cancer care and survival experiences of extremely poor people with cancers of great public health and human significance-breast and colon cancer-we have consistently observed that health insurance does not only matter, but indeed is critical. Adequate health insurance, be it private or public, seems to be strongly associated with access to the best available treatments and outcomes for all Americans. But for women, particularly women with the most treatable types of cancer such as localized, node negative (NN) breast cancer, health insurance seems to all but completely mediate or buffer the profoundly disadvantaging effects of poverty. We also observed two distinct, but theoretically related interactions of poverty and health insurance. First, the advantaging effects of health insurance were much stronger in low poverty neighborhoods, where less than five percent of the households were poor, than in high poverty neighborhoods, where thirty percent or more of the households were poor (Gorey et al. 2013; Gorey et al. 2012). Such high poverty neighborhoods have been described as places of prevalent demographic vulnerability that are particularly distressed for their lack of social and economic capital (Wilson 2012; Jargowsky 1997; Jargowsky \& Bane 1991). It appears that women with breast cancer in more affluent neighborhoods, where more facilitative social and economic capital is available, are probably better able to absorb the indirect and direct, but uncovered, costs of care. Second, among MA women, the advantaging effects of health insurance were particularly strong in a certain type of high poverty neighborhood, that is, in barrios where the majority of the residents were MA (KMG, unpublished observations). Though seemingly paradoxical, such findings are consistent with the theory that MA barrios, even though they tend to be places of high poverty, may provide their residents with relatively more instrumental social and economic supports (Aranda et al. 2011; Markides \& Eschbach
2005; Eschbach et al. 2004; Suarez 1994; Markides \& Coreil 1986). This demonstrates that the effects of health insurance do not operate in a social vacuum. Health insurance surely matters, but so too does place and culture.

It seems that the interacting effects of being uninsured or underinsured, being poor and being an ethnic minority woman of color have been rather well studied during the post-diagnostic phase of breast cancer care. Much less is known about the diagnostic phase of care even though a number of studies have suggested that having adequate health insurance coverage at least partially mediates poverty and MA screening disadvantages (Miranda et al. 2011; Garcia et al. 2012; Gonzalez et al. 2012). It has already been established in this context that MA women are much less likely than NHW women to be diagnosed relatively early with $\mathrm{NN}$ breast cancer (KMG, unpublished observations), a type of breast cancer that has not yet spread to any regional lymph nodes and so typically has an excellent prognosis. Aiming to advance theoretical and practical understandings about this ethnic diagnostic gap, we advanced these hypotheses. First, the MA-NHW diagnostic gap is mediated by health insurance. Second, among NHW women the health insurance-early diagnosis relationship is moderated by poverty such that health insurance is less effective in high poverty neighborhoods. And third, among MA women in high poverty neighborhoods, the health insurance-early diagnosis relationship is moderated by barrio status such that health insurance is more effective in MA barrios.

\section{Methods}

The sampling frame was the California cancer registry. Study participants were originally randomly selected from three geographic and three socioeconomic place strata. Geographic strata were very large metropolitan areas (San Diego, San Francisco and Los Angeles), smaller metropolitan areas (Salinas, Modesto, Stockton, Bakersfield and Fresno) and rural places. Socioeconomic strata were based on the prevalence of poor households in census tractdefined neighborhoods: high poverty ( $30 \%$ or more), middle poverty (5\% to $29 \%$ ) and low poverty (less than $5 \%$ poor (Census Bureau 2002)). Data was obtained for 303 MA and 3,611 NHW women with breast cancer, diagnosed and staged between 1996 and 2000, who were originally followed until 2011. Most of the MA women were identified directly through medical records $(77.8 \%)$, the remainder through a validated algorithm using Hispanic surnames and maiden names, birthplace, race and other record linkages (sensitivity $=84.4 \%$ and specificity $=99.1 \%$ (NAACCR Race and Ethnicity Work Group 2009)). MA barrios were defined as neighborhoods where $50 \%$ or more of the residents were MA in 2000. We explored other barrio criteria from $33 \%$ to $75 \%$ MA. The $50 \%$ criterion had the most predictive validity for these analyses. Health 
insurance and breast cancer care variables were extracted from hospital and physician office charts and clinic reports.

We used logistic regression models to test hypotheses about the mediating and moderating effects of poverty and health insurers in predicting binary (node negative or positive) breast cancer stage at diagnosis. Odds ratios (OR) and 95\% confidence intervals (CI) were estimated. We also provided practical assessments more germane to clinical or policy significance. All rates were directly adjusted for age and tumor grade using this study's sample as the standard. Then we used standardized rate ratios (RR) for all between-group comparisons with pooled 95\% CIs. Statistical model tests are presented in tables. Practical significance indices are presented in the text. Other methodological details have been reported (Gorey et al. 2013; Gorey et al. 2012).

\section{Results}

\section{Description of samples}

Descriptive characteristics of the MA and NHW samples of women with breast cancer are displayed in Table 1. All of the unadjusted, statistically significant, comparisons seemed quite consistent with existing knowledge. MA women, approximately nine of every ten of whom were first generation immigrants, were much more likely to live in high poverty, large urban neighborhood barrios and to be either uninsured or insured by Medicaid. Furthermore, annual household incomes among MAs were much lower than NHWs (median income of $\$ 26,000$ versus $\$ 52,225$, median test $p<.05$ ). Typically being more than a decade younger at diagnosis than their NHW counterparts (median age of 49.5 versus 62.5, median test $p<.05$ ), the MA women were more likely to have never been married and less likely to be widowed. Finally, breast tumors among the MA women were more advanced and less well differentiated.

\section{Mediation and moderation of the ethnicity-early breast cancer diagnosis relationship}

Significant, otherwise unadjusted, age- and grade-adjusted effects of ethnicity, poverty and primary health insurer on early diagnosis of $\mathrm{NN}$ breast cancer are displayed in the top of Table 2. Moving down the table to the fully adjusted regression model, the apparent effect of being MA $(\mathrm{OR}=0.77 ; 95 \% \mathrm{CI}=0.60,0.99[\mathrm{RR}=0.87 ; 95 \% \mathrm{CI}=$ $0.80,0.94])$ was no longer significant in the presence of health insurance and poverty $(\mathrm{OR}=1.12 ; 95 \% \mathrm{CI}=0.77$, 1.63). In fact, when poverty was removed from the model the MA effect remained null $(\mathrm{OR}=1.08 ; 95 \% \mathrm{CI}=0.76$, 1.54, data not shown). Having private health insurance or Medicare coverage seemed to completely mediate the MANHW disparity on early breast cancer diagnosis. The mechanism of such mediation seems to be through a rather complex 3-way interaction of ethnicity, poverty and
Table 1 Place, socioeconomic, demographic and tumor descriptive profiles: Mexican American and non-Hispanic white women

\begin{tabular}{|c|c|c|c|c|}
\hline \multirow[t]{2}{*}{ Variable } & \multicolumn{2}{|c|}{ Mexican American ${ }^{a}$} & \multicolumn{2}{|c|}{ Non-Hispanic white } \\
\hline & Sample & Percentage & Sample & Percentage \\
\hline \multicolumn{5}{|l|}{ Geographic place $^{*}$} \\
\hline Large urban & 130 & 42.9 & 1,065 & 29.5 \\
\hline Smaller urban & 85 & 28.1 & 1,278 & 35.4 \\
\hline Rural & 88 & 29.0 & 1,268 & 35.1 \\
\hline \multicolumn{5}{|c|}{ Neighborhood poverty prevalence, $\%$} \\
\hline$<5$ & 28 & 9.2 & 1,525 & 42.2 \\
\hline $5-29$ & 77 & 25.4 & 1,300 & 36.0 \\
\hline$\geq 30$ & 198 & 65.3 & 786 & 21.8 \\
\hline \multicolumn{5}{|c|}{ Neighborhood Mexican American prevalence, \% } \\
\hline$<25$ & 50 & 16.5 & 2,721 & 75.4 \\
\hline $25-49$ & 83 & 27.4 & 617 & 17.1 \\
\hline$\geq 50$ & 170 & 56.1 & 273 & 7.6 \\
\hline \multicolumn{5}{|l|}{ Primary health insurer ${ }^{*}$} \\
\hline Uninsured & 61 & 20.1 & 299 & 8.3 \\
\hline Medicaid & 74 & 24.4 & 134 & 3.7 \\
\hline Medicare & 54 & 17.8 & 1,082 & 30.0 \\
\hline Private & 114 & 37.6 & 2,096 & 58.0 \\
\hline \multicolumn{5}{|l|}{ Age at diagnosis, ${ }^{*}$} \\
\hline $25-44$ & 98 & 32.3 & 411 & 11.4 \\
\hline $45-54$ & 78 & 25.7 & 762 & 21.1 \\
\hline $55-64$ & 66 & 21.8 & 768 & 21.3 \\
\hline$\geq 65$ & 61 & 20.2 & 1,670 & 46.2 \\
\hline \multicolumn{5}{|l|}{ Marital status $^{*}$} \\
\hline Married & 178 & 59.9 & 2,002 & 56.6 \\
\hline Never married & 52 & 17.5 & 369 & 10.4 \\
\hline Separated or divorced & 28 & 9.5 & 467 & 13.2 \\
\hline Widowed & 39 & 13.1 & 700 & 19.8 \\
\hline \multicolumn{5}{|l|}{ Histological grade } \\
\hline I, well differentiated & 38 & 12.5 & 891 & 24.7 \\
\hline II, moderately & 110 & 36.3 & 1,556 & 43.1 \\
\hline $\begin{array}{l}\text { III or IV, poorly } \\
\text { differentiated }\end{array}$ & 155 & 51.2 & 1,164 & 32.2 \\
\hline \multicolumn{5}{|l|}{ Summary stage ${ }^{*}$} \\
\hline $\begin{array}{l}\text { Local-regional, node } \\
\text { negative }\end{array}$ & 169 & 55.8 & 2,485 & 68.8 \\
\hline $\begin{array}{l}\text { Local-regional, node } \\
\text { positive }\end{array}$ & 126 & 41.6 & 1,013 & 28.1 \\
\hline Distally metastasized & 8 & 2.6 & 113 & 3.1 \\
\hline
\end{tabular}

${ }^{a}$ Most (88\%) were first generation immigrants born in Mexico and this characteristic did not differ significantly between barrio and non-barrio residents.

${ }^{*} p<.05$ for between-ethnic group difference ( $x^{2}$ test). 
Table 2 Logistic regression main effects and interactions of ethnicity, neighborhood poverty and primary health insurers on early diagnosis of node negative breast cancer

\begin{tabular}{|c|c|c|}
\hline $\begin{array}{l}\text { Predictor variables } \\
\text { (Baseline Comparison) }\end{array}$ & $\begin{array}{l}\text { Odds } \\
\text { ratio }\end{array}$ & $\begin{array}{l}95 \text { percent } \\
\text { confidence interval }\end{array}$ \\
\hline \multicolumn{3}{|c|}{ Separate main effect models } \\
\hline \multicolumn{3}{|l|}{ Ethnicity (Non-Hispanic white) } \\
\hline Mexican American & 0.77 & $0.60,0.99$ \\
\hline \multicolumn{3}{|l|}{ Neighborhood poverty (low poverty) } \\
\hline Middle poverty & 0.92 & $0.78,1.08$ \\
\hline High poverty & 0.79 & $0.66,0.94$ \\
\hline \multicolumn{3}{|c|}{ Primary health insurer (uninsured or Medicaid) } \\
\hline Private or Medicare & 1.38 & $1.14,1.67$ \\
\hline \multicolumn{3}{|c|}{ Full model } \\
\hline \multicolumn{3}{|l|}{ Ethnicity (Non-Hispanic white) } \\
\hline Mexican American & 1.12 & $0.77,1.63$ \\
\hline \multicolumn{3}{|l|}{ Neighborhood poverty (low poverty) } \\
\hline Middle poverty & 0.95 & $0.80,1.12$ \\
\hline High poverty & $0.86^{*}$ & $0.71,1.03$ \\
\hline \multicolumn{3}{|c|}{ Primary health insurer (uninsured or Medicaid) } \\
\hline Private or Medicare & 1.40 & $1.13,1.73$ \\
\hline $\begin{array}{l}\text { Ethnicity by neighborhood poverty by } \\
\text { primary health insurer }\end{array}$ & $0.64^{*}$ & $0.39,1.07$ \\
\hline
\end{tabular}

Notes: All effects were age and grade-adjusted. After these covariates, ethnicity, poverty, health insurance and their interactions were accounted for, geographic place and marital status did not enter the full model. Barrio was not entered as it was not theoretically or hypothetically meaningful for NHW women. ${ }^{*} p<.10$.

health insurance. This effect moderation, meaning essentially that the effect of the 2-way poverty by health insurance interaction differs by ethnicity, is depicted in Table 3.

Separate MA and NHW regression models are displayed in the table. Of first note is the lack of main effects in the presence of significant interactions. Only the main effect of health insurance was significant for NHW women (OR = 1.72 , right column), the Medicare or privately insured (69.5\%) being $13 \%$ more likely to be diagnosed with $\mathrm{NN}$ disease than were the Medicaid or uninsured $(61.5 \%, \mathrm{RR}=$ $1.13 ; 95 \% \mathrm{CI}=1.05,1.21)$. The poverty by health insurer interaction depicted near the bottom of the table indicates, as hypothesized, that the advantaging effect of having adequate health insurance, Medicare or private, was larger in low poverty neighborhoods $(\mathrm{OR}=1.75)$ than in middle to high poverty neighborhoods $(\mathrm{OR}=1.29)$ for NHW women. As for practical significance, the size of the adequate insurance-early diagnosis effect in low poverty neighborhoods (respective early diagnosis rates among adequately and inadequately insured of $70.8 \%$ vs. $59.0 \%, R R=1.20$; $95 \% \mathrm{CI}=1.06,1.36)$ was nearly twice the size of the effect in higher poverty neighborhoods $(68.5 \%$ vs. $61.4 \%, R R=$ $1.12 ; 95 \% \mathrm{CI}=1.02,1.23)$.
The poverty by barrio by health insurer interaction among MA women is depicted at the bottom of the table. As hypothesized, the advantaging effect of having adequate health insurance, Medicaid or private, was largest in MA barrios even though they were all also high poverty neighborhoods. In fact, these were the only places were health insurance seemed to have a significant protective effect $(\mathrm{OR}=2.09)$ for MA women. And in a practical sense, the effect was quite large. In barrios, the Medicaid or privately insured (73.9\%) were $45 \%$ more likely to be diagnosed with NN disease than were the uninsured or those covered by Medicare $(50.8 \%, \mathrm{RR}=1.45 ; 95 \% \mathrm{CI}=1.11,1.89)$. Furthermore, such adequately insured barrio residents (73.9\%) even seemed to enjoy early diagnoses at a rate on par with similarly well insured NHW women who lived in relatively affluent neighborhoods $(70.8 \%, \mathrm{RR}=1.04 ; 95 \% \mathrm{CI}=0.91$, 1.19). Finally, we noted that MA barrio residents were more likely to be married (63.9\%) and typically had slightly higher annual household incomes (median $=\$ 24,600)$ than MAs who lived in similarly high poverty, but non-barrio neighborhoods (44.6\% and $\$ 22,525$, both $\chi^{2}$ and median tests, $p<.05)$. There was also a non-significant trend for more barrio residents to have adequate health insurance coverage $(60.2 \%$ vs. $50.8 \%)$.

\section{Discussion}

MA women with breast cancer were much less likely to have been diagnosed relatively early, before their disease had spread to regional lymph nodes, but this MA-NHW disparity was completely mediated by the main and interacting effects of health insurance. Advantages of health insurance were largest in low poverty neighborhoods for NHW women, while among MA women they were, paradoxically, largest in high poverty MA barrios. In fact, the highest rate of early NN breast cancer diagnosis was among such MA women with adequate health insurance who lived in MA barrios, with three-quarters having $\mathrm{NN}$ disease at the time of their diagnosis. Consistent advantages of being privately insured were also observed for all study participants, MA and NHW, with Medicare coverage seemingly more instrumental for the older cohort of NHW women and Medicaid coverage more so for the poorer cohort of MA women.

It seems that the effectiveness of public and private health insurance programs is significantly impacted by the availability of other key resources. In more wellto-do neighborhoods where social and economic capital abound most NHW women with breast cancer seem quite able to absorb the indirect and additional uncovered, direct costs of care. High poverty neighborhoods on the other hand, with their relative lack of such capital reserves, seem to remain as described more than a generation ago by William Julius Wilson, places of "true disadvantage" (Wilson 2012), especially for the women who live 
Table 3 Logistic regression main effects and interactions of neighborhood poverty and primary health insurer on early diagnosis of node negative breast cancer for Mexican American and non-Hispanic white women

\begin{tabular}{|c|c|c|c|c|c|c|c|c|c|}
\hline \multirow{2}{*}{\multicolumn{2}{|c|}{ Predictor Variables }} & \multicolumn{4}{|c|}{ Mexican American } & \multicolumn{4}{|c|}{ Non-Hispanic White } \\
\hline & & Sample & OR & \multicolumn{2}{|c|}{$(95 \% \mathrm{Cl})$} & \multicolumn{2}{|l|}{ Sample } & OR & $(95 \% \mathrm{Cl})$ \\
\hline \multicolumn{10}{|l|}{ Neighborhood poverty } \\
\hline \multicolumn{2}{|l|}{$<5 \%$ poor } & 28 & 1.00 & & & \multicolumn{2}{|l|}{1,525} & 1.00 & \\
\hline \multicolumn{2}{|l|}{$5-29 \%$ poor } & 77 & 1.07 & \multicolumn{2}{|c|}{$(0.40,2.89)$} & 1,300 & & 0.90 & $(0.76,1.07)$ \\
\hline \multicolumn{2}{|l|}{$>30 \%$ poor } & 198 & 0.66 & \multicolumn{2}{|c|}{$(0.26,1.69)$} & \multicolumn{2}{|l|}{786} & 0.84 & $(0.68,1.04)$ \\
\hline \multicolumn{10}{|c|}{ Neighborhood Mexican American prevalence } \\
\hline \multicolumn{2}{|l|}{$<50 \%$} & 133 & 1.00 & & \multicolumn{2}{|l|}{3,338} & 1.00 & \\
\hline \multicolumn{2}{|l|}{$>50 \%$ (Barrio) } & 170 & 0.68 & \multicolumn{2}{|c|}{$(0.36,1.27)$} & \multicolumn{2}{|l|}{273} & 0.99 & $(0.74,1.33)$ \\
\hline \multicolumn{10}{|l|}{ Primary health insurer } \\
\hline \multicolumn{2}{|c|}{ Uninsured or underinsured ${ }^{a}$} & 115 & 1.00 & & 433 & & 1.00 & \\
\hline \multirow{2}{*}{\multicolumn{2}{|c|}{ Adequately insured ${ }^{b}$}} & 188 & 0.87 & $(0.44$ & & 3,178 & & 1.72 & $(1.31,2.27)$ \\
\hline & & \multicolumn{4}{|c|}{ Poverty by barrio by insurer } & \multicolumn{4}{|c|}{ Poverty by insurer } \\
\hline \multicolumn{2}{|l|}{ Significant interactions } & 303 & $2.33^{*}$ & \multicolumn{2}{|c|}{$(0.94,5.82)$} & 3,611 & & 1.61 & $(1.07,2.42)$ \\
\hline \multicolumn{10}{|c|}{ Poverty by insurer interaction for non-Hispanic white women } \\
\hline & & \multicolumn{4}{|c|}{$<5 \%$ poor } & \multicolumn{4}{|c|}{$>5 \%$ poor } \\
\hline Predictor Variables & & Sample & OR & $(95$ & & Sample & & OR & $(95 \% \mathrm{Cl})$ \\
\hline Primary health insurer & & & & & & & & & \\
\hline Uninsured or Medicaid & & 129 & 1.00 & & & 304 & & 1.00 & \\
\hline Private or Medicare & & 1,396 & 1.75 & $(1.20$ & & 1,782 & & $1.29^{*}$ & $(0.99,1.67)$ \\
\hline & & overty by $k$ & by insurer & action fo & exican & rican women & & & \\
\hline & & & & & & $>30 \% \mathrm{p}$ & ooor & & \\
\hline & & $<30 \%$ po & & $<5$ & Mexicar & nerican & $>5$ & Mexican & herican \\
\hline & Sample & OR & $(95 \% \mathrm{Cl})$ & Sample & OR & $(95 \% \mathrm{Cl})$ & Sample & OR & $(95 \% \mathrm{Cl})$ \\
\hline Primary health insurer & & & & & & & & & \\
\hline Uninsured/Medicare & 30 & 1.00 & & 32 & 1.00 & & 53 & 1.00 & \\
\hline Private/Medicaid & 75 & 1.45 & $(0.58,3.60)$ & 33 & 0.69 & $(0.22,2.11)$ & 80 & $2.09^{*}$ & $(0.96,4.58)$ \\
\hline
\end{tabular}

Notes: All effects were adjusted for age, grade and all other main and interaction effects. Adjustment of the MA regression model for birthplace made no practical difference in findings.

a Uninsured or Medicare for MA women and uninsured or Medicaid for NHW women.

${ }^{b}$ Private insurance or Medicaid for MA women and private insurance or Medicare for NHW women.

${ }^{*} p<.10$.

there. Not only are they much more likely to be uninsured or underinsured (Gorey et al. 2013; Gorey et al. 2012), but even when publicly or privately insured, these programs seem much less effective there than they are in places of lower poverty. Seemingly paradoxically, even within high poverty neighborhoods, a very strong advantaging effect of having health insurance was observed among MA women who lived in barrios where the majority of their neighbors were MA. These findings in support of the "barrio advantage" theory, suggest that adequate health insurance, in concert with other social and economic resources that may be more available in largely MA neighborhoods likely potentiate each other. It stands to reason that having the additional capital of either private or public health insurance could operate to potentiate the strengths and resiliencies that already seem to exist in barrios.

\section{Gateway Mexican American neighborhoods}

By purposefully oversampling women with breast cancer from some of the poorest neighborhoods in California, it seems that we also oversampled recent immigrants among our MA subsample. In fact, nine of every ten of the MA women in our study were first generation immigrants. The extremely low-income barrios we studied were comprised typically (70\%) of MAs who were also almost exclusively (90\%) first generation immigrants. High immigrant "gateway" Hispanic neighborhoods in Los Angeles were recently validated through mixed-methods by the geographer Regan Maas (Maas 2011). Her nuanced analyses found much support for the notion that it is such "first point of contact" places where countries of origin, for example, Mexican cultural norms, are probably strongest and so social capital is strongest and most supportive. The MA barrios we studied 
were consistent with Maas' gateway neighborhood criteria (prevalent low-income and high-immigrant populations) as it seems was the specificity of the health protective effects we observed. Both general health benefits that she observed in Los Angeles and the cancer diagnostic advantages that we observed across California were restricted to low-income, high-immigrant gateway neighborhoods. Furthermore, Maas' qualitative findings of "tight knit, close mutigenerational social networks of family members" that seem most strongly associated with practical economic, health and even health care benefits in gateway neighborhoods are consistent with a generation of sociological theorizing that seem a very good fit with our findings on MA women with breast cancer (Portes \& Bach 1985; Palloni \& Morenoff 2001; Haas et al. 2004).

Our finding of earlier breast cancer diagnosis among MA women who resided in MA barrios or gateway neighborhoods was inconsistent with two previous studies that found later diagnoses in Hispanic enclaves (Keegan et al. 2010b; Reyes-Ortiz et al. 2008). Those other studies, however, studied more ethnically diverse Hispanic women. Likely of more importance is that they studied somewhat higher income neighborhoods that included substantially more second, third and even fourth generation immigrants. Maas also described such neighborhoods and confirmed that they do not seem to offer the same sorts of bonding social capital or health protections that gateway neighborhoods do. She theorized that later, more acculturated, immigrant cohorts have weaker connections to cultural traditions and so probably offer each other increasingly less instrumental social support.

\section{Potential limitation}

We think that some of our analyses were statistically powerful, especially the ethnicity-health insurance-early diagnosis mediation hypothesis test that analyzed the experiences of nearly 4,000 women. That analysis provided rather precise effect estimates that may engender substantial confidence. Admittedly, certain moderator hypotheses we examined, especially those related to the increasingly specific experiences of the nearly $200 \mathrm{MA}$ women in high poverty neighborhoods and who lived in MA barrios $(n=133)$ and were adequately or inadequately insured (respective samples of 80 and 53) were increasingly exploratory. Also, this observational study did not provide the direct means of making causal inferences. However, we think that its findings are consistent with well-established causal criteria. For example, they seem quite theoretically plausible in that they are consistent with much extant sociological theory and they seem consistent with much research that has been accomplished across diverse geographic and methodological contexts. We hope that researchers with access to national data will advance confidence in this field's knowledge by systematically replicating these analyses.
This study has a key strength as well. In focusing on diagnosis we think that we effectively ruled out the most prevalent confound explanations for Hispanic-paradoxical or barrio mortality advantages. First, through mathematical modeling we essentially matched MA and NHW women on two proxies of disease virulence: age and tumor grade. Therefore, the two analytic groups were similarly diseased or relatively health, making the healthy immigrant alternative explanations unlikely. Second, the fact that we observed MA barrio advantages during the initial phase of diagnostic breast cancer care probably also effectively ruled out return migration or so-called "salmon bias" as well as other selective mortality explanations.

\section{Conclusion}

These findings reaffirm the preventive impact of health insurance especially among those at greatest risk of not having adequate coverage. They are also consistent with the theory that more facilitative social and economic capital is available to MA women in barrios and to NHW women in more affluent neighborhoods. It is there that each respective group of women with breast cancer is probably best able to absorb the indirect and direct, but uncovered, costs of care. Policy makers need to understand that even covered health care presently comes with myriad of costs. And while many seem able to absorb them, many others do not.

\section{Ethical standards}

This study was reviewed and cleared by the University of Windsor research ethics board.

\section{Competing interests}

The authors declare that they have no competing interests.

\section{Authors' contributions}

$\mathrm{SH}$ conceptualized and performed the secondary analysis and led the writing. KMG supervised the analysis and writing. KMG, INL and $\mathrm{CH}$ obtained funding. All authors assisted with study design, data analysis and writing, and read and approved the final manuscript.

\section{Acknowledgements}

This research was supported in part with funds from the Canadian Institutes of Health Research (grant 67161-2). The authors gratefully acknowledge the administrative and logistical assistance of Kurt Snipes, Janet Bates and Gretchen Agha of the Chronic Disease Surveillance and Research Branch, California Department of Public Health. We also gratefully acknowledge the research and technical assistance of Nancy Richter and Daniel Edelstein of the University of Windsor and Mark Allen, Allyn Fernandez-Ami and Arti Parikh-Patel of the California Cancer Registry. Finally, we are grateful for the assistance we received from Eric Holowaty of the University of Toronto and Guangyong Zou of the University of Western Ontario in obtaining funding. The collection of cancer incidence data used in this study was supported by the California Department of Public Health as part of the statewide cancer reporting program mandated by California Health and Safety Code Section 103885; the National Cancer Institute's Surveillance, Epidemiology and End Results Program under contract HHSN261201000140C awarded to the Cancer Prevention Institute of California, contract HHSN261201000035C awarded to the University of Southern California, and contract HHSN261201000034C awarded to the Public Health Institute; and the Centers for Disease Control and Prevention's National Program of Cancer 
Registries, under agreement U58DP003862-01 awarded to the California Department of Public Health. The ideas and opinions expressed herein are those of the authors and endorsement by the State of California, Department of Public Health the National Cancer Institute, and the Centers for Disease Control and Prevention or their contractors and subcontractors are not intended nor should be inferred.

\section{Author details}

${ }^{1}$ School of Social Work, University of Windsor, 401 Sunset Avenue, Windsor, Ontario N9B 3P4, Canada. ²Department of Geography, University of Western Ontario, London, Ontario, Canada. ${ }^{3}$ Windsor Regional Cancer Center, Windsor, Ontario, Canada. ${ }^{4}$ Department of Medicine, Division of General Internal Medicine, School of Medicine and Dentistry, University of Western Ontario, London, Ontario, Canada.

\section{Received: 6 May 2013 Accepted: 16 May 2013}

Published: 28 June 2013

\section{References}

Acosta PS (2010) Inequality and health care access: a mixed-methods study of the experiences of Mexican origin families in California (doctoral dissertation), State University, Michigan

Aranda MP, Ray LA, Snih SA, Ottenbacher KJ, Markides KS (2011) The protective effect of neighborhood composition on increasing frailty among older Mexican Americans: a barrio advantage? J Aging Health 23(7):1189-1217

Berube A, Frey WH (2005) A decade of mixed blessings: urban and suburban poverty in census 2000. In: Berube A, Katz B, Lang RE (eds) Redefining urban and suburban America: evidence from census 2000. Brookings Institution Press, Washington

Cagney KA, Browning CR, Wallace DM (2007) The Latino paradox in neighborhood context: the case of asthma and other respiratory conditions. Am J Public Health 97(5):919-925

Census Bureau US (2002) 2000 Census of population and housing in California: summary tape file 3 on CD-ROM. US Government Printing Office, Washington

DeNavas-Walt C, Proctor BD, Smith JC (2012) US census bureau, current population reports (P60-245). income, poverty, and health insurance coverage in the united states: 2011. US Government Printing Office, Washington

Eschbach IK, Ostir GV, Patel KV, Markides KS, Goodwin JS (2004) Neighborhood context and mortality among older Mexican Americans: is there a barrio advantage? Am J Public Health 94(10):1807-1812

Garcia RZ, Carvajal SC, Wilkinson AV, Thompson PA, Nodora JN, Komenaka IK, Brewster A, Cruz Gl, Wertheim BC, Bondy ML, Martínez ME (2012) Factors that influence mammography use and breast cancer detection among MexicanAmerican and African-American women. Cancer Causes Control 23(1):165-173

Gonzalez P, Castaneda SF, Mills PJ, Talavera GA, Elder JP, Gallo LC (2012) Determinants of breast, cervical and colorectal cancer screening adherence in Mexican-American women. J Community Health 37(2):421-433

Gorey KM, Luginaah IN, Holowaty EJ, Fung KY, Hamm C (2009) Breast cancer survival in Ontario and California, 1998 to 2006: Socioeconomic inequity remains much greater in the United States. Ann Epidemiol 19(2):121-124

Gorey KM, Luginaah IN, Bartfay E, Fung KY, Holowaty EJ, Wright FC, Hamm C, Kanjeekal SM (2011) Effects of socioeconomic status on colon cancer treatment accessibility and survival in Toronto, Ontario, and San Francisco, California, 1996-2006. Am J Public Health 101(1):112-119

Gorey KM, Luginaah IN, Holowaty EJ, Zou G, Hamm C, Bartfay E, Kanjeekal SM, Balagurusamy MK, Haji-Jama S, Wright FC (2012) Effects of being uninsured or underinsured and living in extremely poor neighborhoods on colon cancer care and survival in California: historical cohort analysis, 1996-2011. BMC Publ Health 12:897

Gorey KM, Luginaah IN, Holowaty EJ, Zou G, Hamm C, Balagurusamy MK (2013) Mediation of the effects of living in extremely poor neighborhoods by health insurance: Breast cancer care and survival in California, 1996 to 2011. Int J Equity Health 12:6

Haas JS, Phillips KA, Sonneborn D, McCulloch CE, Baker LC, Kaplan CP, Pérez-Stable EJ, Liang SY (2004) Variation in access to health care for different racial/ethnic groups by the racial/ethnic composition of an individual's county of residence. Med Care 42(7):707-714

Jargowsky PA (1997) Poverty and place: Ghettos, barrios, and the American city. Russell Sage, New York

Jargowsky PA (2005) Stunning progress, hidden problems: the dramatic decline of concentrated poverty in the 1990s. In: Berube A, Katz B, Lang RE (eds)
Redefining urban and suburban America: evidence from census 2000 Brookings Institution Press, Washington

Jargowsky PA, Bane MJ (1991) Ghetto poverty in the United States. In: Jencks C, Peterson PE (eds) The urban underclass. The Brookings Institution, Washington, pp 1970-1980

Kaiser Family Foundation (2012) Medicaid enrollment: June 2011 snapshot (pub no 8050-05). The Kaiser Commission on Medicaid and the Uninsured, Washington Kaplan MA, Inguanzo MM (2011) The social implications of health-care reform: reducing access barriers to health care services for uninsured Hispanic and Latino Americans in the united states. Harvard J Hispanic Policy 23:83-92

Keegan THM, John EM, Fish KM, Alfaro-Velcamp T, Clarke CA, Gomez SL (2010a) Breast cancer incidence patterns among California Hispanic women: differences by nativity and residence in an enclave. Cancer Epidemiol Biomarkers Prev 19(5):1208-1218

Keegan THM, Quach T, Shema S, Glaser SL, Gomez SL (2010b) The influence of nativity and neighborhoods on breast cancer stage at diagnosis and survival among California Hispanic women. BMC Cancer 10:603

Maas RM (2011) Breaking bonds: the effect of spatially segmented cultural adaptation on overall health for Hispanics/Latinos in Los Angeles. Dissertation. University of California, Los Angeles

Mair C, Diez Roux AV, Osypuk TL, Rapp SR, Seeman T, Watson KE (2010) Is neighborhood racial/ethnic composition associated with depressive symptoms? The multi-ethnic study of atherosclerosis. Soc Sci Med 71(3):541-550

Markides K, Coreil J (1986) The health of Hispanics in the southwestern united states: an epidemiological paradox. Public Health Rep 101(3):253-265

Markides KS, Eschbach K (2005) Aging, migration, and mortality: current status of research on the Hispanic paradox. J Gerontol B Psychol Sci Soc Sci 60(2):68-75

Miranda PY, Tarraf W, González M (2011) Breast cancer screening and ethnicity in the united states: implications for health disparities research. Breast Cancer Res Treat 128(2):535-542

NAACCR Race and Ethnicity Work Group (2009) NAACCR guideline for enhancing Hispanic-Latino identification: Revised NAACCR Hispanic/Latino identification algorithm. North American Association of Central Cancer Registries, Springfield, IL

Osypuk TL, Bates LM, Acevedo-Garcia D (2010) Another Mexican birthweight paradox? The role of residential enclaves and neighborhood poverty in the birthweight of Mexican-origin infants. Soc Sci Med 70(4):550-560

Palloni A, Morenoff JD (2001) Interpreting the paradoxical in the Hispanic paradox: demographic and epidemiologic approaches. Ann N Y Acad Sci 954:140-174

Portes AL, Bach RL (1985) Latin journey: Cuban and Mexican immigrants in the United States. University of California Press, Berkeley

Reyes-Ortiz CA, Eschbach K, Zhang DD, Goodwin JS (2008) Neighborhood composition and cancer among Hispanics: tumor stage and size at time of diagnosis. Cancer Epidemiol Biomarkers Prev 17(11):2931-2936

Suarez L (1994) Pap smear and mammogram screening in Mexican American women: the effects of acculturation. Am J Public Health 84(5):742-746

Wilson WJ (2012) The truly disadvantaged: the inner city, the underclass, and public policy, 2nd edn. University of Chicago Press, Chicago

doi:10.1186/2193-1801-2-285

Cite this article as: Haji-Jama et al:: Health insurance mediation of the Mexican American non-Hispanic white disparity on early breast cancer diagnosis. SpringerPlus 2013 2:285

\section{Submit your manuscript to a SpringerOpen ${ }^{\circ}$ journal and benefit from:}

- Convenient online submission

- Rigorous peer review

- Immediate publication on acceptance

- Open access: articles freely available online

- High visibility within the field

- Retaining the copyright to your article

Submit your next manuscript at $>$ springeropen.com 